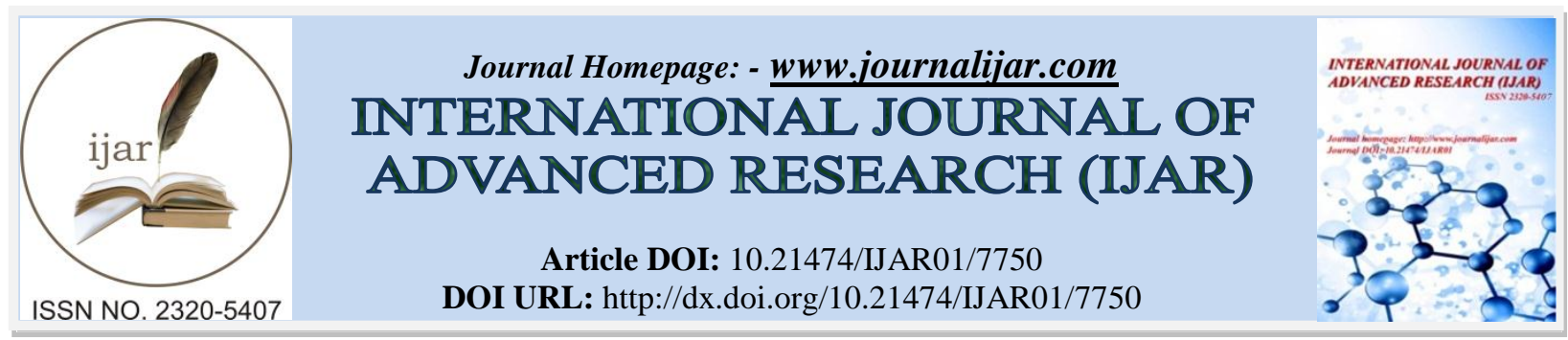

RESEARCH ARTICLE

\title{
NEST STRUCTURE AND NESTING ECOLOGY OF FERAL PIGEON (Columba livia) IN NANDED, MAHARASHTRA STATE.
}

\author{
Shivaji P. Chavan, Komal B. Reddy and Pawan L. Jadhav \\ Department of Zoology, School of Life Sciences, Swami Ramanand Teerth Marathwada University, Nanded, \\ Maharashtra State. PIN - 431606, India.
}

\section{Manuscript Info}

Manuscript History

Received: 23 July 2018

Final Accepted: 29 August 2018

Published: September 2018

Keywords:-

Nesting, Ecology, Pigeon, Columba

livia, SRTMUN

\begin{abstract}
Feral pigeon Columba livia is one of the common bird species inhabiting in manmade structures though it may go for feeding away from nesting places. Cement concrete made buildings in use for Govt. departmental offices, educational Institutions, wear houses, sports complex, students hostels are mainly used by this species for nesting. In the current study it has been found adapted for use of readily available plant material to construct the nest. From observed three different types of total 133 nests $95 \%$ were active and reused, $5 \%$ were abandoned nests. Clutch size was 2 eggs per nest with overlapped breeding in $68.5 \%$ nests. Safety of the nest and developing young, rich source of nesting material at selected nesting sites were the most preferred factors identified as main cause of expanding population of this pigeon. No predation of the eggs or young ones was recorded. Nuisance of faecal debris of this pigeon everyday in the main entrance corridor and office building verandas was most notable.
\end{abstract}

Copy Right, IJAR, 2018,. All rights reserved.

\section{Introduction:-}

Shelter is the most essential need of animals. For self protection and safety of dependent progeny the young ones, various animals use the readily available shelters, modify it or construct the specially designed nests. Birds such as Robin, Bulbul, and House sparrow build and refurnish their nest even after hatching of their eggs and when the young ones open their eyes they are demonstrated by the parents how the nest is built and kept in good condition, this is one type of animal behaviour of parental care. Probably this early age imprinting become long lasting till the young one become adults. But most of the information about building nest is imprinted in the genes of the avian species itself.

Many species in various families of birds re-use their nests; almost all raptors including eagles, hawks, falcons, vultures, etc. have the same nest site and usually the same nest structure year after year. It needs a lot time and efforts to build the nest, there are many bird species like cormorants, herons, storks, weaver birds, egrets that prefers to build communal nesting colonies. They often reuse the same nest sites and a part of their old nest but always add more nest material and repair the damaged region or upgrade to a higher quality nests. Basically any nest takes too much time and efforts to rebuild it but in many birds such as Indian blue rock Pigeon, red vented Bulbul etc. the old nest is often repaired and reused unless there's some serious reason such as attacks by predators, human disturbance or destruction of nesting site. Present study deals with the reuse and reconstruction of old nests by common bird that prefer to live near human habitation the Blue rock pigeon (Columba livia) to determine nest structure, nest material 
and selection site for the nesting. The feral pigeon mainly prefer to build nest in city centres for breeding (Sacchi et al. 2002). Some ground nesting birds like Yellow wattled lapwings every year construct new nest due to their annual breeding patterns the old nests destroyed by various factors and they try to select new area every year (Shivaji et. al., 2016). There are effects of urbanization on nesting behaviour of this species (Anil Tripathi, 2016).

The Domestic pigeon (Columba livia domestica) live and raise their young ones only in residential areas in the readymade carton or wooden boxes which are specially designed and constructed by their owners to fix on the terrace, windows or trees. The domestic pigeons are raised for the commercial, food and hobby purpose. Unlike Domestic pigeon the feral pigeon (Columba livia) construct and build their own nest to raise their young ones. The nest of rock pigeon can be seen under the roof of buildings, lintel, on window shields, rock crevices, in or above readymade boxes such as fuse box, electric pump starter box, air conditioner box (A/C), metal boxes etc. The rock pigeon nest seems simple and basic structure rather than having complex structure generally seen in many birds such as Baya weaver (Ploceus philippinus) (Achegave et al., 2016). The material of feral Rock Pigeon nest consist of long straight grass sticks, Dried leaf sticks of Neem tree (Azadiracta indica), dried leaf sticks of Shankasur plant (Caesalpinia pulcherrima) and central rachis sticks of tree leaves that are roughly straight or slightly curved and unbranched. The nest shape is generally constructed by fixing these sticks one up on others. The shape of nest is not seen uniform as it depends up on the place, location and availability of space. Many nests were found constructed by placing only few sticks on slope to avoid rolling of eggs from selected site. Generally these types of nests were seen in the dug wells and rock crevices where usually a depression is present. Some unusual nesting materials mainly pieces of various plastic goods from garbage wastes are also found in the Pigeon nest as an unusual materials (Soniya V. P., 2002).

The feral rock pigeon also known as Indian blue rock pigeon it is a member of family Columbidae. It is commonly known as "Parva" in Marathi language of Maharashtra State. It is approximately 18-20 inches in size (including tail length). Generally the body weight of this pigeon ranges from 250-350 gm. The wingspan is 20-26 inches in range. Sexes look nearly identical, although males are slightly larger than female and have more iridescence on their neck plumage. The body colour variable, but wild birds are gray in colour. This bird is one of the most abundant species of Indian subcontinent and it comes under Least Concerned (LC) species category of IUCN due to the large population found all over India. Sometimes it is also categorized under title of pests (Murton et. al., 1972). Pigeons are often found in pairs during breeding season. Wild, domestic and feral pigeons typically mate for life time. Although their long-term bonds are unbreakable and socially monogamous, but extra-pair mating do occur, often initiated by males. Reproduction is oviparous. The female pigeons reach sexual maturity as early as 7 months of age; there is pair selection (Burley N, 1997). In 8 to 12 days after mating, the female lays 1 to 3 (usually 2) white eggs (Fig. 10, 20) which hatch after 18 days incubation (Murton et al. 1972). Both the male and female incubate the eggs but female incubates during the night. The young ones leave the nest in 25 to 29 days after hatching. Initially the young are fed "Crop milk" (regurgitated thick liquid food from the parent's crops). More eggs are laid before the first clutch leaves the nest. The average clutch time is around 2 month approximately if the food availability is abundant. Breeding may occur in all seasons. Pigeon species show different plumage patterns within the same species (Hetmanski and Jarosiewicz (2008). The feral pigeons never built the nests close to ground or on the objects on the ground or as open ground nests of Yellow wattled lapwing (Tomasz and Elzbieta, 2005), Black winged Stilts, Golden ringed plovers, Red Wattled Lapwing.

\section{Materials and Methods:-}

For this investigation study area- S. R. T. M. University, campus at Nanded was selected. Swami Ramanand Teerth Marathwada University, Nanded, Maharashtra State is having 650 acre area with thick vegetation found in different regions surrounded by open wood lands dominated by Babool (Acacai nilotica), Ber (Zizipus mauritiana), Sagvan (Tectona grandis), Neem (Azadiracta indica), Shankasur (Caesalpinia pulcherrima) and number of shrubs are also found in the University campus area. Already there are reports on the occurrence of this pigeon species in the University area and its nuisance value (Chavan et al. 2015). The University campus include more than 25 buildings out of which 17 buildings were selected for this study due to presence of feral pigeon nesting at these sites. The selected area was found good for the feral pigeon nesting and breeding due to available resources and abundance of nesting places (Achegave et al. 2016; Jadhav et al. 2018). The study area includes the cement concrete buildings and infrastructures which are quite old but provides good habitat for the feral pigeon nesting (Kalsi and Kalsi, 1992). The Nikon P510 (42 X zoom $14 \mathrm{MP}$, point and shoot) camera was used to take photographs from safe distance without disturbing the birds and their nest. Post capture photo processing was done by using Microsoft Picture Manager for the basic editing. The photographs were labelled using Microsoft Paint Software. During this 
study only photographs of the birds, bird nests, eggs and chicks were taken. A good quality binocular was also used for tracing the birds from distance. To determine the nesting ecology of the Feral Rock Pigeon in the various habitats of the University campus data was collected by observations through the trekking method, general observations, bird watching methods, and field observations. The data was collected during November 2017 to April 2018. The feral rock pigeon nests were categorized on the basis of their shape as whole nests or roughly rounded, half circular and irregular nests. The species of bird was identified by using standard references (Grimmett et al. 2011). The area selected in the University campus was divided in to 4 parts A, B, C and D by using Google map for the convenience. For the calculations on nest specifications and nest density per building line transect method was used. The selected area specifications in this study were mainly the cement concrete buildings.

Area A: School of Pharmacy, School of Commerce and management, School of Computational Sciences, School of Social Sciences, S .R. T. M. University Guest house

Area B: Girl's Hostels, School of Educational Sciences, School of Fine and Performing Art, School of Media and Mass Communication Studies and Central Library.

Area C: School of Languages, Literature and Culture Studies, School of Interdisciplinary Studies, School of Earth Sciences, School of Chemical Sciences.

Area D: School of Physical Sciences, School of Life Sciences, Administrative building, A dug well near S. R. T. M. University main entrance gate near highway.

\section{Results and Discussion:-}

The structure and shape of feral pigeon nest was quite simple and basic. The shape of nest was not uniform as it depends up on the place, location (where it built?) and availability of space. The material of these nests consists of straight, long, un-branched, dry leaves sticks of Neem tree (Azadiracta indica) and Shankasur flower plant (Caesalpinia pulcherrima) and some grass sticks having nearly same structure. Nest constructed by fixing these sticks one upon others. The size and length of the material chosen was not uniform. As we observed the structure of the feral pigeon's nests can be divided into three types such as 1) Whole nest or roughly circular Nest, 2) Half Circular Nest, 3) Irregular Nest.

\section{Whole nest or roughly circular nest:}

The size and length of plant material used for building of nest by feral pigeon seems almost uniform hence most of the time nest was of roughly circular or rounded in shape. Therefore the nests are constructed by feral pigeon generally at the places where the space is good enough for the completion of circumference of nest (Above fuse boxes, A/C boxes, under the roof, Window shield, lintel etc.) (Fig.1-20). Circular nest usually ranges from approximately $22-25 \mathrm{~cm}$ i.e. outer circumference of the nest as shown in (Fig. 2). While inner circumference of the nest cup was $10-12 \mathrm{~cm}$. In the nest cup area one individual at once with eggs or chick fits barely. Once the chicks come out of the eggs and start to grow up to large size and unable to fit in the nest, chicks get of the nest and feeding is given near to the nest. During this stage another set of eggs were found in most of the nests as observed.

\section{Half circular Nest:}

The half circular nests were observed at the ready made available places where the safe nest can be constructed such as in the readymade boxes (fuse boxes, iron boxes etc.). This type of nests are covered or guarded by the wall or any other covering from one or two sides (Fig. 3.). Hence the Pigeon pair constructs the nest of half size only. This type of nest seems unstable but it remains at its place for long time because no disturbance as compared to whole nest or circular nest. The size and shape of such nest depends up on the site where it is built.

\section{Irregular nest:}

These types of nests are generally seen at the places where pit or depression is already present. The nest constructed only by placing few plant sticks on the slope area to prevent rolling of eggs (Fig. 4.). Such type of nest can be seen at the plain places also. This type of nest indicates the brood pair needs less construction efforts, though this type of nest seems basic but it works well to raise the chicks. During this study total 133 numbers of nests of Feral Rock Pigeon were observed in selected study area Swami Ramanand Teerth Marathwada University Campus, Nanded. In Area 'A' 31, area 'B' 52, area 'C' 25 and in area ' $D$ ' 25 nests were found. The percentage occupied by nests according to area A, B, C, D recorded was $23 \%, 39 \%, 19 \%$ and $19 \%$ respectively (Table 2.). Study area 'B' among A, B, C, D represents greatest nest density. The percentage nesting according to site of nesting was $20 \%$ in or above readymade boxes, $33 \%$ under the roof of building, $13 \%$ above the lintel and 33\% on window shield. It was found that major habitat preferred by the Feral Rock Pigeon for their nesting site was human habitation and few sites 
which can be included in their natural nesting sites. Only $1 \%$ nests out of 133 were found in natural nesting habitation such as rock crevices, rock gaps and rock holes etc. 95\% nests among 133 were reconstructed and under reuse in successive breeding cycle by the same Pigeon pair and considered as active nests, while very few of the nests were abandoned (5\%). There are factors like infection by mites and lice to rock dove that decide the reproductive success that indirectly related to nest building in these birds.

This is the first ever study report in Nanded region on the nesting ecology of Feral Rock Pigeon. The density of nests was depending up on the availability of space and type of shelter where the nests were built. These nests were abundantly found all over the study area especially near the human habitation on cement concrete buildings and infrastructures under the roofs, in or above the readymade boxes such as fuse box, electric starter box, A/C boxes etc. Besides these Feral Rock Pigeon nests are also found in its natural habitation such as the rock crevices, holes and gaps in rocks, inside the wells, rock walls etc. There are several reasons such as destruction of their natural habitat, increasing urbanization ${ }^{[3]}$ and scarcity of food etc. due to which Feral Rock Pigeon preferring their nesting site in and around human habitation. Hence increasing population of this species is causing increasing troubles for humans as well as for themselves. Feral Rock Pigeon reuse and rebuild their nests year after year this results in deposition of their faecal matter in and around the nest and nesting material due to which humans destroy their nests and nesting sites in order to save beauty of buildings, statues, heritage monuments and other nesting sites. Present study is very important documented data that define and express valuable information about nesting ecology of this species that will be useful for researchers, students, department of forest, Government of Maharashtra and common peoples. The nesting in birds to correlate nest-building behaviour to the origin and early evolution of passerine birds (Order Passeriformes) and supported evidence for the hypothesis that the combination of small body size and the ability to place a constructed nest where the bird chooses, helped make possible a vast amount of adaptive radiation (Chavan et al. 2016, Collias NS, 1997). Cavity or hole nests (in ground or tree), open-cup nests (outside of holes), and domed nests (with a constructed roof) were all present very early in evolution of the Passeriformes, as indicated by the presence of all three of these basic nest types among the most primitive families of living passerine birds. Each basic type of nest built by passerines has advantages and disadvantages in specific ecological situations, and nest type depends on a balance of multiple factors that involve the nest site, the physical environment, the community, size and behaviour of the birds. In the present study the space and food availability for feral pigeon found to cause increase in nest density in human habitation area. It is stated in a study (Hetmanski and Wolk, 2005) that clutch overlap is a reproductive strategy of the Feral Pigeon, which results in an increase in the number of clutches produced by a pair and increase in the number of young raised. It is dependent on the time length for care of clutch and the interval between two successive clutches. It was also found that nesting conditions like the number of nests in a breeding pair's territory, brood size and location of the nest in the colony. It also influences the duration of clutch care, the length of clutch interval and the degree of clutch overlap. The clutch interval was shorter when parents only cared for one young, than when two young were in the nest. Breeding pairs with large territories that included two nests had shorter clutch intervals than those pairs with only one nest. In the present study the clutch overlap was 1-2\% amongst the observed 133 nests. A census on feral pigeons (Sacchi et al. 2002) (Columba livia); in Milan, Italy in $181 \mathrm{~km}^{2}$ area to examine population densities in different urban habitats and the relationships between population density and structural features of buildings found that the pigeon population was 103650 birds, with an average density of $570 / \mathrm{km}^{2}$. There was a positive relationship between both bird number and flock number and the abundance of buildings constructed before 1936 indicated active selection of old buildings by feral pigeons. Here the selection of concrete buildings for nesting by the pigeon indicates adaptation to existing conditions that favours in other aspects like safety and availability of places for nesting and food resource that was not found in the research by Socchi et al. (2002). In the similar study which was designed to determine the ecology of feral pigeon (Columba livia) in the urban areas of Rawalpindi/Islamabad, Pakistan (Ali et. al., 2016) the roosting sites, nesting sites, food and water points did differ in different seasons. Highest population of the pigeon was recorded in old buildings (0.30 individual/ha) and lowest in parklands ( 0.008 individual/ha). In this study also population density of the pigeon mainly concentrated in old buildings; roosting sites, nesting sites, food and water points used by pigeons changed with respect to different seasons. These results also coincide with present observations. The age of nest also influenced the breeding season (Hetmanski, 2004). Many other factors were found to cause nesting and incubation related damages that includes eggs and nestling loss, mechanical damage to eggs, eggs and nestlings falling out of the nests, embryo death, competition among fledglings and nestlings disease were dependent on the level of pigeons reproductive activity, especially in overly dense colonies. The well built nests with high stability protect the brood from falling (Coon et al. 1981) whereas in the present study important factor observed related to nest damage was routine cleaning of some of the buildings otherwise at $90 \%$ places approximately all nests were safe and breeding was successful. It was first study of its kind to determine the nest structure and nest density in S. R. T. M. University 
campus Nanded. We are of the opinion that this data will be useful for further planning and building extensions, to decide the designs of buildings, regular maintenance of the buildings so as to control the pigeon population and keep away these birds to prevent their nuisance value. It is clear that the breeding pairs of feral pigeon use the same nesting sites for many years when confirmed its safety though they have to go for long distance for foraging (Hetmanski and Wolk, 2005).

\section{Acknowledgements:-}

Authors are thankful to UGC-New Delhi, the camera purchased under the Major Research Project (F. No. MRP-1165 (SR) 11/07/2012.) Sanctioned to corresponding author (SPC). Other equipments purchased under this project were also extremely useful during this research.

Table 1:- Location and Number of nests observed in study area S. R. T. M. University, Nanded.

\begin{tabular}{|c|c|c|c|c|c|c|}
\hline \multirow{2}{*}{$\begin{array}{l}\text { Sr. } \\
\text { No. }\end{array}$} & \multirow{2}{*}{$\begin{array}{c}\text { Name of Department/ Building } \\
\text { /Structure }\end{array}$} & \multicolumn{5}{|c|}{ Locations of Nest } \\
\hline & & $\begin{array}{c}\text { In/ above } \\
\text { Readymade } \\
\text { Box }\end{array}$ & $\begin{array}{l}\text { Under the } \\
\text { Roof }\end{array}$ & Lintel & $\begin{array}{l}\text { Window } \\
\text { Shield }\end{array}$ & Total \\
\hline \multicolumn{7}{|c|}{ Area A: total number of nests $=31$} \\
\hline 1 & School Of Pharmacy & 02 & - & 02 & 03 & 07 \\
\hline 2 & School Of Computational sciences & - & - & - & 04 & 04 \\
\hline 3 & $\begin{array}{l}\text { School Of commerce and } \\
\text { Management }\end{array}$ & - & 01 & 01 & 03 & 05 \\
\hline 4 & School Of Social Sciences & - & 03 & 01 & 06 & 10 \\
\hline 5 & S.R.T. University Guest house & 01 & 02 & 01 & 01 & 05 \\
\hline \multicolumn{7}{|c|}{ Area B: total number of nests $=52$} \\
\hline 6 & $\begin{array}{l}\text { Girl's Hostel S. R. T. M. } \\
\text { University Nanded. }\end{array}$ & 16 & 10 & 08 & 06 & 40 \\
\hline 7 & School Of Educational Sciences. & - & 01 & 03 & 02 & 06 \\
\hline 8 & $\begin{array}{l}\text { School Of Fine and Performing } \\
\text { Arts }\end{array}$ & 01 & 01 & - & 03 & 05 \\
\hline 9 & $\begin{array}{l}\text { School Of Media and Mass } \\
\text { studies }\end{array}$ & - & - & - & 01 & 01 \\
\hline 10 & Central Library & - & - & - & - & 0 \\
\hline \multicolumn{7}{|c|}{ Area C: : total number of nests $=25$} \\
\hline 11 & $\begin{array}{l}\text { School of Language and } \\
\text { Literature and culture studies }\end{array}$ & - & 04 & - & 03 & 07 \\
\hline 12 & School of Interdisciplinary & - & - & - & 01 & 01 \\
\hline 13 & School of Earth Sciences & 03 & 04 & - & 04 & 11 \\
\hline 14 & School of Chemical Sciences & - & 06 & - & - & 06 \\
\hline \multicolumn{7}{|c|}{ Area D: total number of nests $=25$} \\
\hline 15 & School of Physical Sciences & 01 & 02 & - & 01 & 04 \\
\hline 16 & School of Life Sciences & - & 02 & - & 02 & 04 \\
\hline 17 & Administrative Building & 02 & 08 & 01 & 04 & 15 \\
\hline 18 & $\begin{array}{l}\text { Dug well near S.R.T.M. } \\
\text { University (main gate) }\end{array}$ & \multicolumn{5}{|c|}{$\begin{array}{l}\text { Feral Rock Dove nest was also found in the rock crevices(1) and PVC } \\
\text { pipe (1). }\end{array}$} \\
\hline
\end{tabular}

Table 2:-Number of nests and percentage in area A, B, C and D at S.R.T.M. University, Nanded.

\begin{tabular}{|c|c|c|c|}
\hline Sr. No. & Area & Total number of nests/ Area & Nest Percentage/ Area \\
\hline 1 & A & 31 & $23 \%$ \\
\hline 2 & B & 52 & $39 \%$ \\
\hline 3 & C & 25 & $19 \%$ \\
\hline 4 & D & 25 & $19 \%$ \\
\hline
\end{tabular}


Table 3:-Location wise Number and percentage of Pigeon nests at different locations in nests in S.R.T.M. University at Nanded (Study area)

\begin{tabular}{|c|c|c|c|}
\hline Sr. No. & Location Of Nest & Total Number of Nest & Nest Percentage \\
\hline 1 & In/Above the readymade boxes & 26 & $20 \%$ \\
\hline 2 & Under the Roof & 44 & $33 \%$ \\
\hline 3 & Above Lintel & 17 & $13 \%$ \\
\hline 4 & Window Shield & 44 & $33 \%$ \\
\hline 5 & Inside Well & 02 & $1 \%$ \\
\hline
\end{tabular}

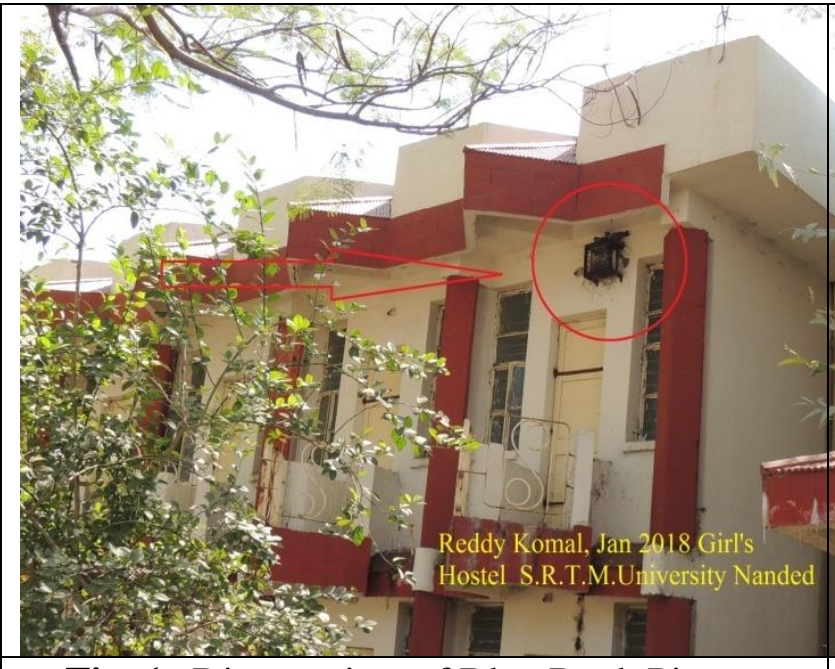

Fig. 1:-Distant view of Blue Rock Pigeon Nest on A/C iron bracket.

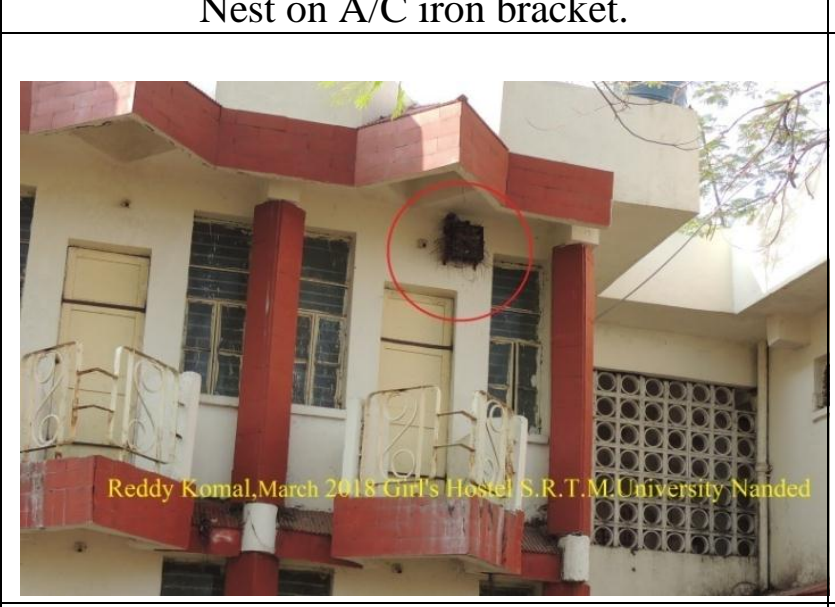

Fig. 3:-Pigeon nest spotted on the same building in Girl's hostel S. R. T. M. University, Nanded

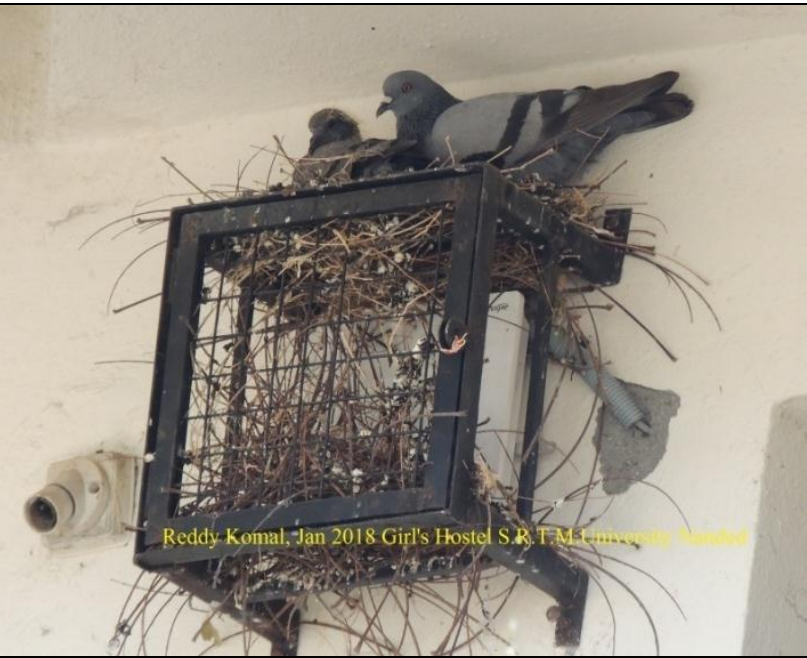

Fig. 2:-Zoomed view of Blue Rock Pigeon Nest on A/C iron bracket.

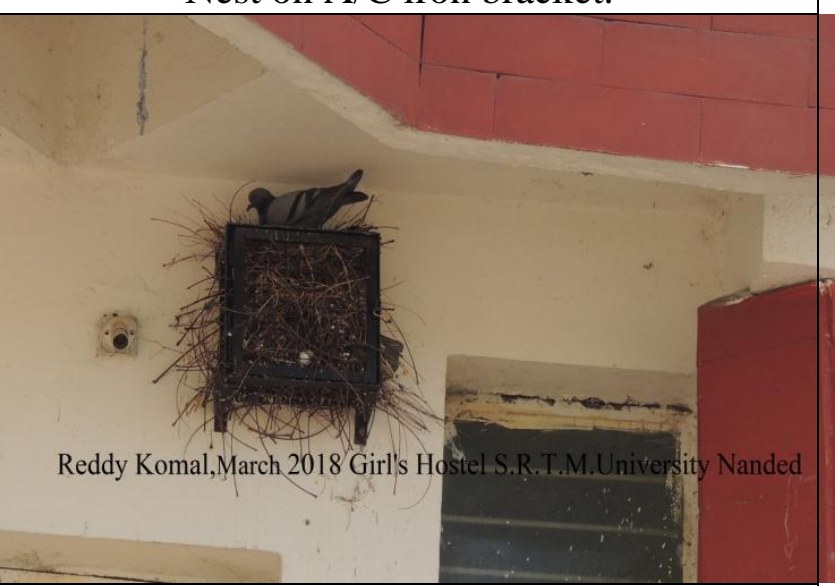

Fig.4:-Reconstruction of same existing nest after few days. 


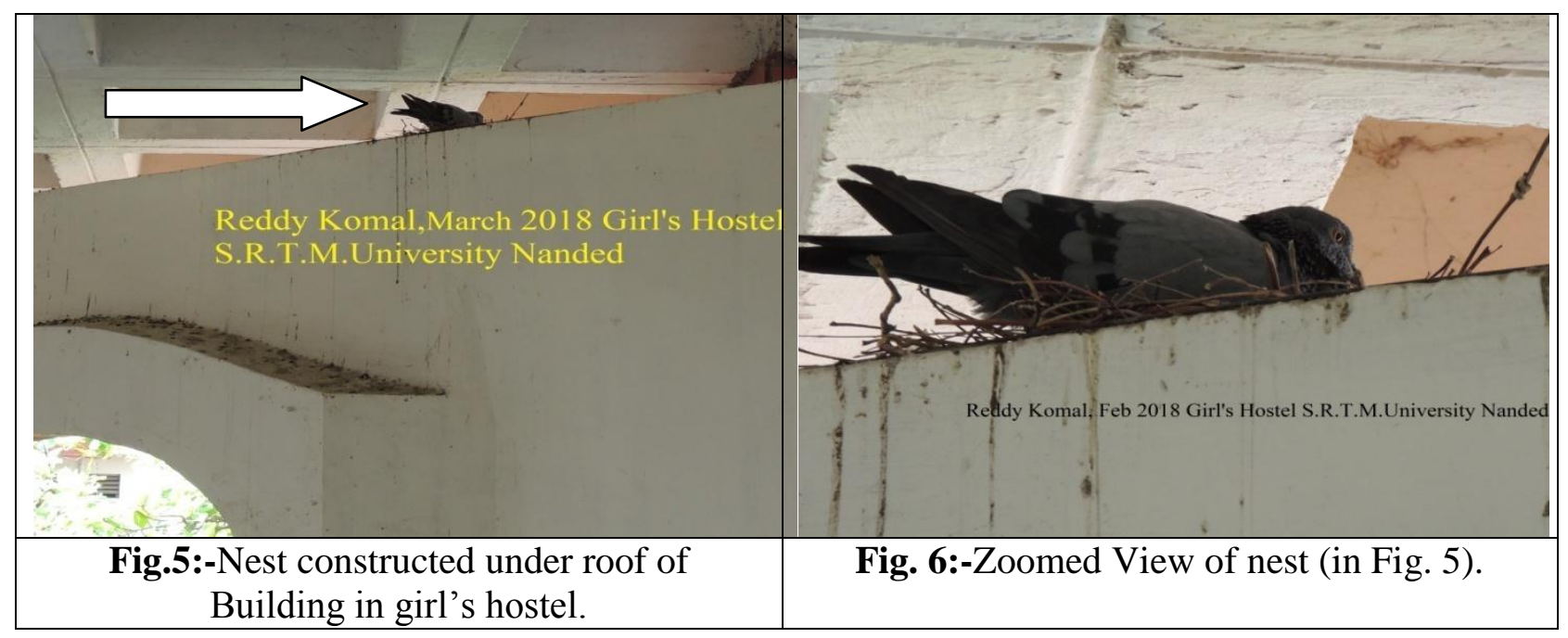

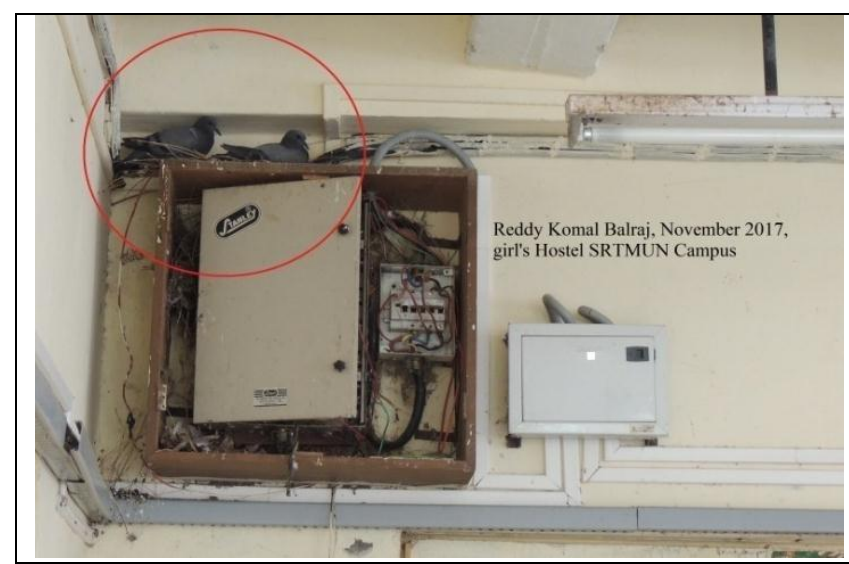

Fig.7:-Nest constructed above fuse box.

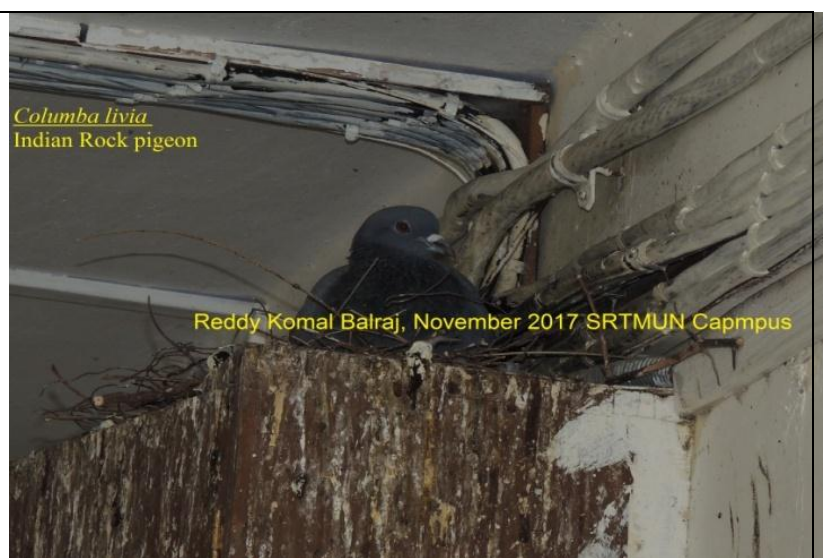

Fig.8:-View of nest constructed above fuse box.

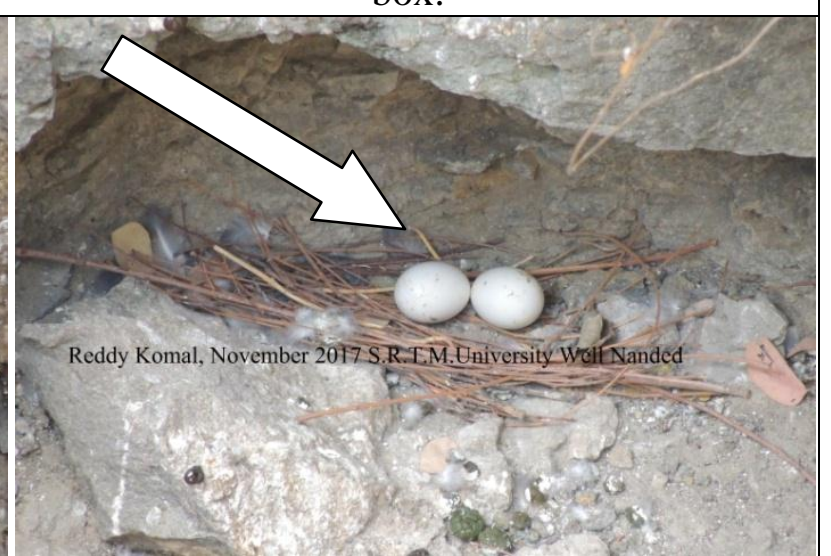

Fig.10:-Nest with eggs in rock crevices of dug well near main gate of S. R. T. M. U. Nanded 


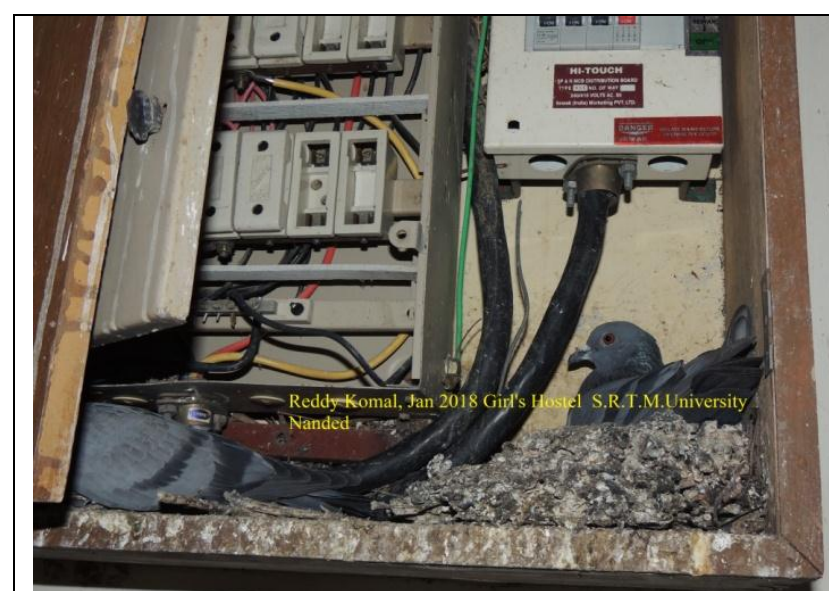

Fig.11:-Nest constructed inside fuse box in Girl's Hostel S.R.T.M.U. Nanded

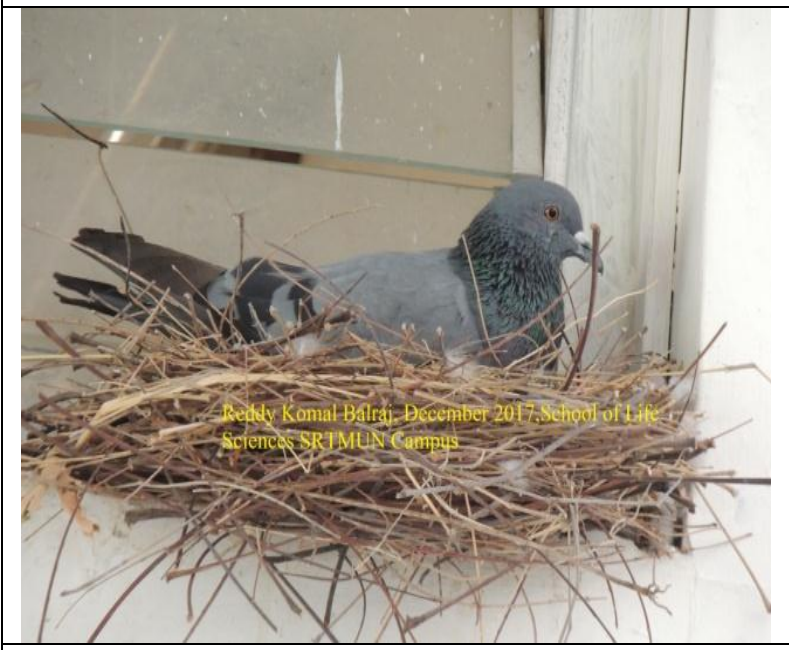

Fig.13:-Zoomed view of Nest School of life sciences, S.R.T.M.U. Nanded

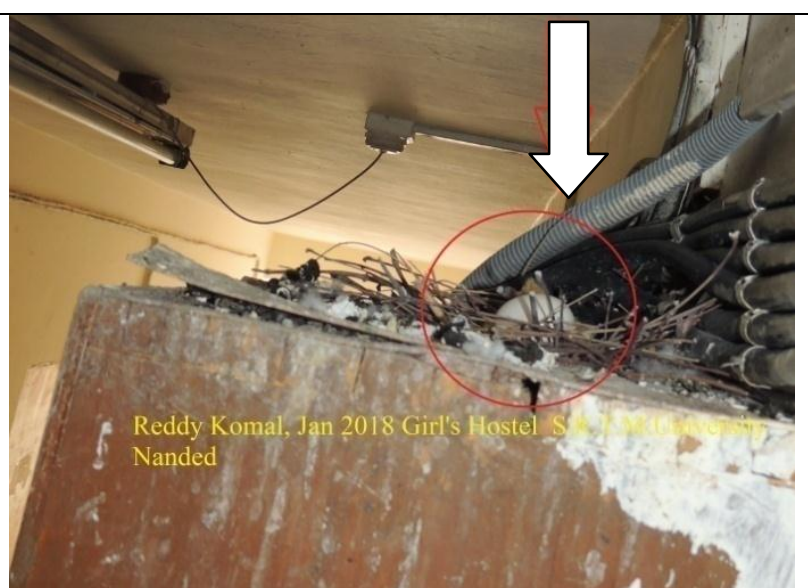

Fig.12:-Nest with eggs above fuse box in girl's hostel S.R.T.M.U. Nanded

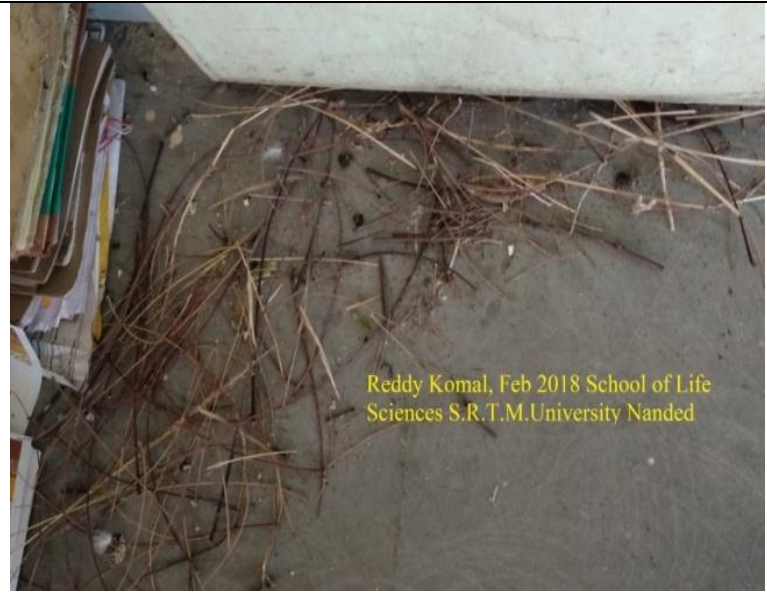

Fig.14. Destroyed nest during cleaning of building premise.

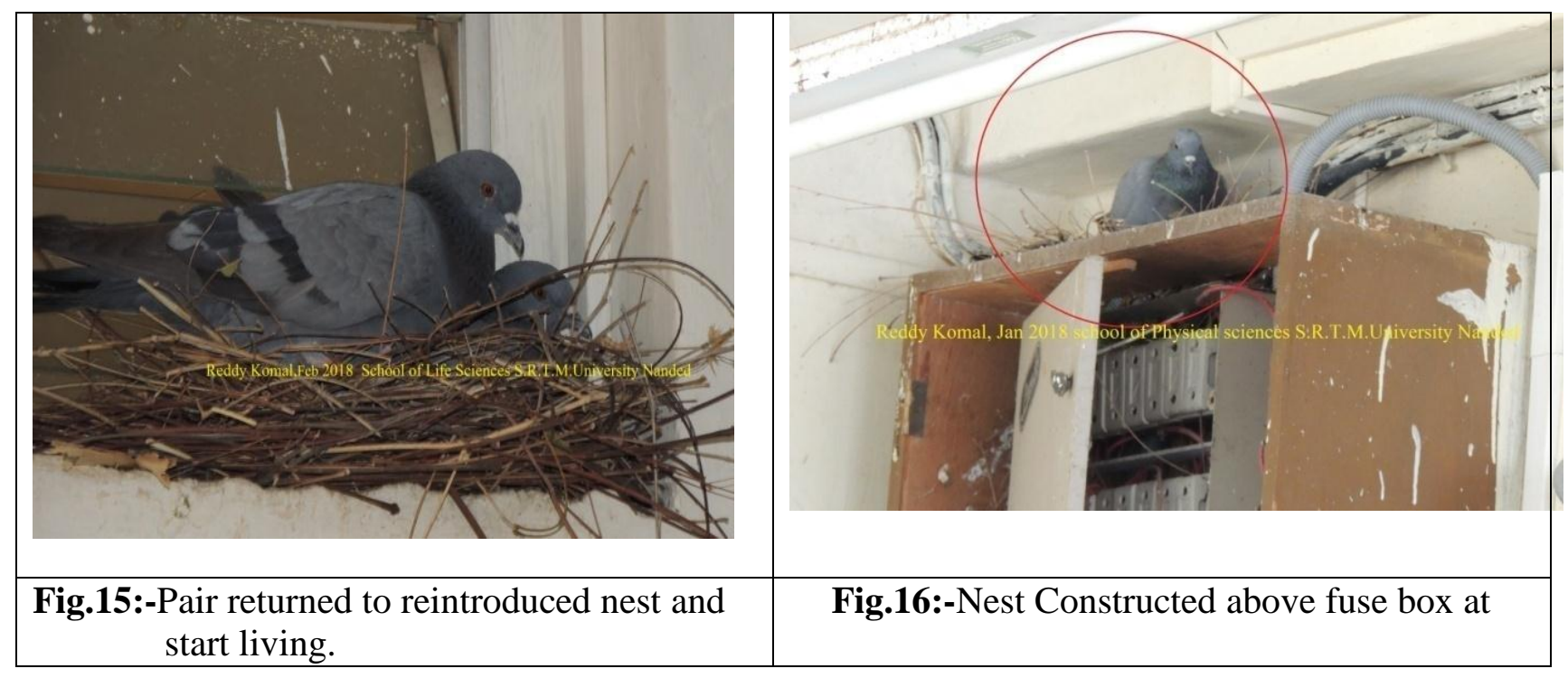




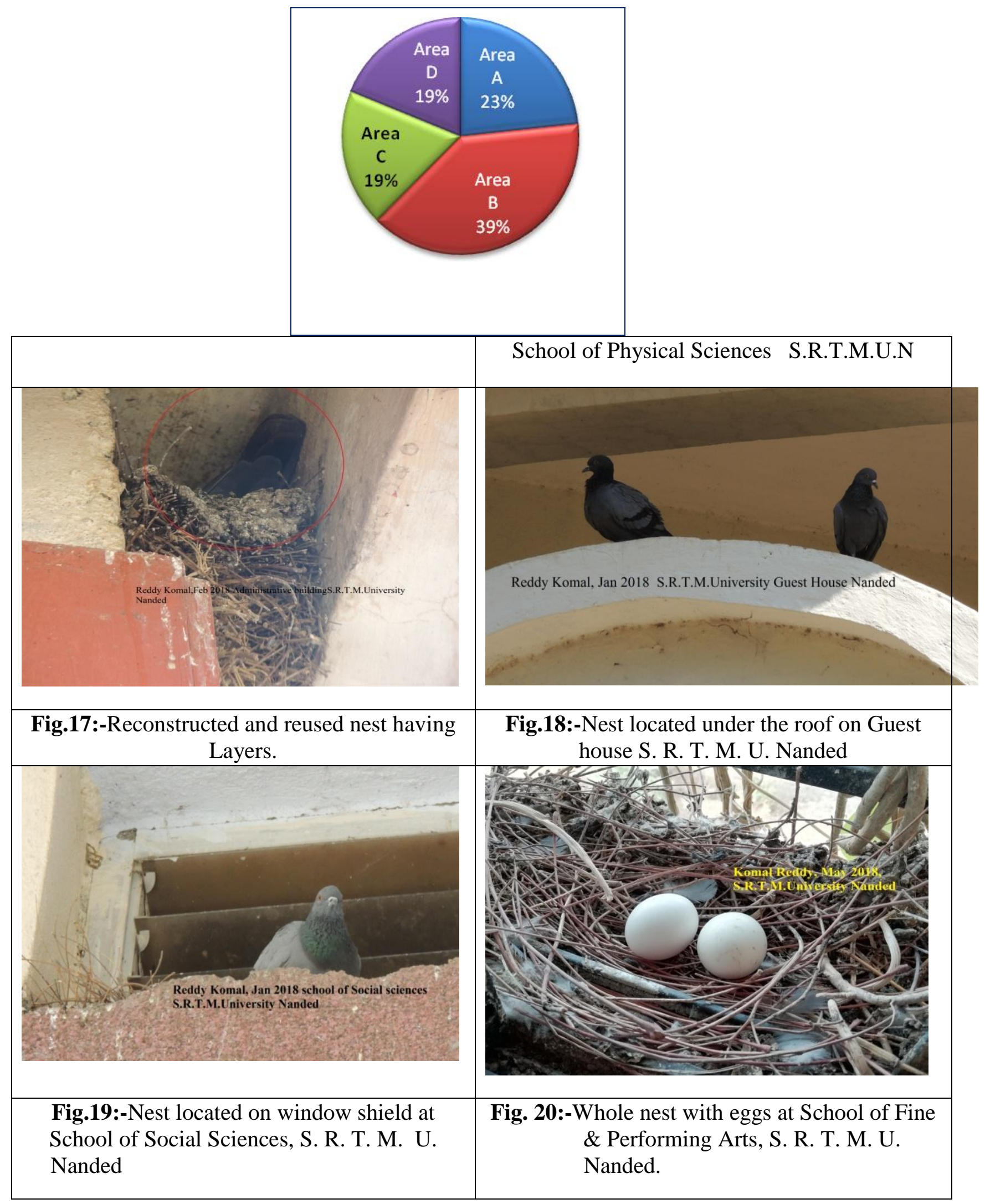


Fig. 21:-Nest percentage of Feral Rock Pigeon in study area A, B,C,D at S.R.T.M.University Nanded.

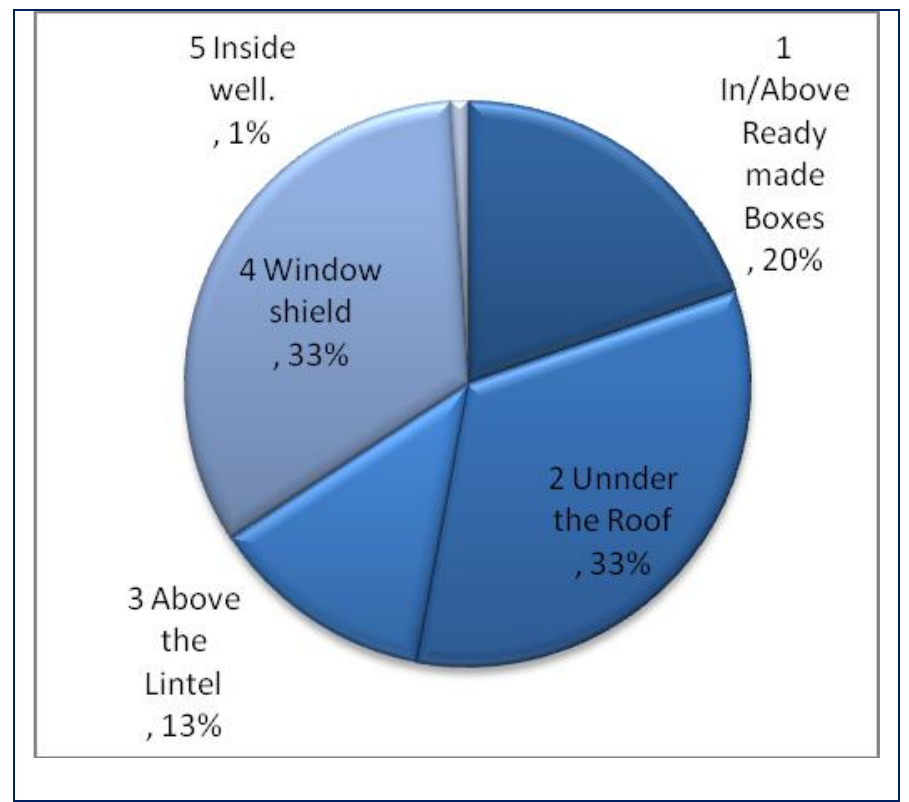

Fig. 22:-Location wise number and percentage of Pigeon nests in S.R.T.M.U.N campus, Nanded.

\section{References:-}

1. Sacchi R, Gentilli A, Razzetti E and Barbieri F. (2002). Effect of building features on density and flock distribution of feral pigeons Columba livia var. Domestica in an urban environment. Can. J. Zool. 80: 48-54.

2. Shivaji Chavan, Rajesh Achegave, Sharda Padghane. (2016). Characters of nesting sites, ground nests and eggs of Yellow-Wattled Lapwing (V. Malabaricus) Aves (Charadridae). Int. Journal of Zoology studies. 1: 12-17.

3. Anil Tripathi. (2016). Effect of urbanization on nest building behaviour of Columba livia domestica (Gmelin, 1789) Int. Res. Jour. of Envi. Sciences 5 (6): 1-5.

4. Achegave RM, Chavan SP, Patil PV and Tarte SH. (2016). Nesting of Baya weaver (Ploceus philippinus) in S. R. T. M. University, Nanded and fields along Asana river at Nanded, Maharashtra, India. Int. J. Curr. Res. Aca. Rev. 4 (6): 51-60.

5. Soniya VP. (2002). Unusual nesting material in the nest of Black rock Pigeon Columba livia. J. Bom. Nat. Hist. Soc. 99: (3) 527.

6. Murton RK, Thearle RJP and Thompson J. (1972). Ecological studies of the feral pigeon Columba livia var. Population, breeding biology and methods of control. 1972; J. Appl. Ecol. 9: 835-874.

7. Burley N. 1997. Parental investment, mate choice and mate quality; Proc. Natl. Acad. Sci. USA. 74(3): 34763479.

8. Hetmanski T, Jarosiewicz A. (2008). Plumage polymorphism and breeding parameters of various feral pigeon (Columba livia GM.) morphs in urban area (Godanski, North Poland). Polish journal of Ecology. 56(4): 683691.

9. Tomasz H, Elzbieta W. (2005). The effect of environmental factors and nesting conditions on clutch overlaps in the pigeon Columba livia F. Urbana (GM). Polish journal of ecology. 53(1): 105-111.

10. Chavan SP, Dudhmal D, Hambarde S and Kulkarni AN. (2015). Birds from Godavari River Basin Nanded district Maharashtra: Annotated list and some new reports. Int. J. C. Res. And Acad. Rev. 3(4): 328-351.

11. Jadhav Mahesh, Chavan Shivaji and Patange Pooja. (2018). Nests and nest materials of birds in SRTM University area at Nanded, Maharashtra State. Int. J. Of Fauna and Bio. Studies. 5 (2-C): 140-147.

12. Kalsi RS and Kalsi R. (1992). Unusual nesting behaviour in domestic pigeon Columba livia. J. Bombay Nat. Hist. Soc. 89: 253-254.

13. Grimmett R, Inskipp C, Inskipp T. (2011). Birds of the Indian Subcontinent ; Christopher Helm London. 10112. 
14. Chavan Shivaji, Dudhmal Dilip and Deepak Walke. (2016). Mud nests of wire-tailed swallow (Hirundo filifera): Biomarkers of ecological niche in Godavari river ecosystem, Nanded, Maharashtra State. Adv. Biores. 7(2): 170-175. DOI: 10. 15515/abr.0976-4585.7.2.170175.

15. Collias NE. (1997). On the origin and evolution of nest building by passerine birds. The condor. A journal of avian biology. 5(1): 106-116.

16. Hetmanski T and Wolk E. (2005).The effect of environmental factors and nesting conditions on clutch overlap in the feral pigeon Columba livia F. Urbana. Pol. J. Ecol. 53: 523-534.

17. Ali S, Allah Rakha B, Iftikhar H, Muhammad SN, Muhammad R. 2016. Ecology of feral pigeon (Columba livia) in urban areas of Rawalpindi/Islamabad; Pakistan journal of zoology. 2014; 45(5):1229-1234.

18. Coon RA, Nichols JD and Percival HF. (1981). Importance of structural stability to success of Mourning Dove nests. Auk. 98: 389-391.

19. Hetmanski T. (2004).Timing of breeding in the feral pigeon Columba livia domestica in Slupsk (NW Poland). Acta ornithological. 39(2): 105-110. 